\title{
Let's Talk
}

\section{Martina Anderson and Ella O'Dwyer Durham Women's Prison}

We increasingly notice that women approach communication and the expression of emotions very differently from men. While men are conditioned to control their feelings, coming to jail was our first conscious encounter with this type of self suppression. It became eminently clear to us how an institution or a social arena can mould and stereotype its members.

Women collect in jail the structured repression of feelings that men learned in childhood. Men appear to bring in that structure from outside and have it intensified in jail; prisoners harden themselves against their own emotional wants, or what are commonly confused with weaknesses. We here found ourselves doing just that - something we would have ridiculed men for doing. For example, we over-censored what we wrote and said, we restricted conversation when screws were listening. The establishment was not allowed to see us cry, and we seemed to care more about what the system thought of us than about the impression with which our loved ones were left. Seeing the dangers of this, we reviewed the system we had adopted for jail and challenged our conditioning as women. This marked the beginning of ongoing change in us.

Male feminist POWs, like those in Long Kesh, claim to have come to recognise and acknowledge the importance of women in the movement and men's traditional repression of them. Such recognition, however, is heavily tested beyond the prison gates, suggesting that these men need to direct and apply their thinking to the community in which they are going to live.

Far from being 'liberated,' these men are repressed threefold. The emotional self-repression to which men are conditioned in society and which was intensified in jail is topped up by the blind illusion that they have been liberated during their sentence. Given that the goal of our struggle is to free ourselves, are we going to allow ourselves to be so suppressed because of a lack of clever and far sighted thinking? The expectation to the self-professed radical is that he/she will extend such liberated thought to the outside world and to their relationships. Imagine the disappointment of long-waiting partners when they feel the emotional gulf between them. No wonder that, after years of waiting, partnerships fall apart.

If we do not inspire confidence and trust in a partner, how can we inspire it in a nation? If liberated views on women fall down before the challenge of application, will theoretical notions about liberation and freedom generally fall just as flat come the real opportunity to change our country? Or is it that the liberation analysis has extended only to the broader question of rights, status, and power, while the liberation of communication has been left off the agenda? 
Such men are to the fore in discussion about the bigger issues of power, women's freedom and so on, while not looking at the need to liberate themselves nor recognising women's relative progress in the area of communication.

The exclusion of the communication issue from the liberation programme may account for the disappointed expectations and the emotional gulf referred to earlier. Can men not see the possible long-term consequences if such a gulf is allowed to go on growing?

Come liberation of both country and women, men are going to have to unburden themselves of the shackles of the threefold conditioning talked of earlier; the silencing effects of conditioning, jail, and the struggle. It would be wrong to blame this gulf on the sacrifices inherent in the struggle. While there are sacrifices to be made, why punish ourselves further? We do not have to wait for 'Brits Out' to unburden ourselves of some of some of this suppression. Do we need machismo to help carry the burden of our war? And who needs the oppressive weight of British and male self oppression borne by women? We don't.

We resent the image traditionally attached to women of nagging, hysterical people who have lost control. We are especially angered by this label when our frustration can be the accumulated effect of years of restriction at the hands of emotionally-constrained men. Accompanying this emotional restriction is a form of machismo which, though generally tolerated in an amused vein, is boring and even unattractive in personal relationships. The typical male self image, whilst difficult to abandon, may be blocking off richer identities behind it. One way of investigating this notion would be to develop and probe the matter within close relationships. This would gain the triple achievement of unburdening oneself of 'machoistic' self restraint, allowing a rich flow of human communication and unburdening women of the loneliness and frustration of trying to understand for two. 